\title{
periferio
}

\section{DESENVOLVIMENTO MORAL E A FRAGMENTAÇÃO DE UMA SOCIEDADE PÓS-MODERNA*}

Igor Guimarães de Azevedo de Araújo ${ }^{1}$

Faculdade Integrada Brasil Amazônia - FIBRA

Carla Azevedo de Luna ${ }^{2}$

Faculdade Integrada Brasil Amazônia - FIBRA

\section{Resumo}

O artigo tem como objetivo mostrar ao leitor uma estrutura de estudos, que levaram a uma teoria universal e estruturalista do desenvolvimento moral das pessoas e da sociedade, e ao mesmo tempo demonstrar a que ponto chegamos. São apresentados estudos que contemplam desde a formação de uma moral universal e estruturalista, com o pensamento do filósofo Immanuel Kant e sua influência para a teoria de Piaget e Kholberg, no desenvolvimento moral de uma pessoa dividida em seus específicos estágios, até os estudos atuais que mostram as conclusões de Bauman sobre a sociedade pós-moderna e suas implicações no âmbito social e pessoal. As consequências de uma fragmentação social em vários aspectos são colocadas à mostra a fim de chamar a atenção do leitor para ter consciência e percepção de sua existência. Um excesso de contradições é posto para o leitor confrontar com a pós-modernidade um quadro negativo de ações presentes, e levar à reflexão do que pode ser alcançado diante do que nós temos atualmente na nossa sociedade.

Palavras Chave: Kant; Piaget; Kohlberg; fragmentação; cultura do tédio

\footnotetext{
* Artigo apresentado como requisito obrigatório para a obtenção do título de Psicopedagoga pela Faculdade Integrada Brasil Amazônia - FIBRA, 2015.

${ }^{1}$ Graduado em licenciatura em física, discente do curso de Pós graduação em Psicopedagoga pela Faculdade Integrada Brasil Amazônia - FIBRA. E-mail: igorwow@hotmail.com

${ }_{2}^{2}$ Professora Orientadora, Mestre em Psicologia. Membro da equipe docente da Faculdade Integrada Brasil Amazônia - FIBRA. E-Mail: carladeluna@gmail.com
} 


\title{
periferio
}

\section{MORAL DEVELOPMENT AND THE FRAGMENTATION OF A POST-MODERN SOCIETY}

\begin{abstract}
The article aims at showing to readers a structure of studies that led to a universal theory, and to the structuralist moral development of people and society, and at the same time demonstrate where we are now. They are studies that contemplate from a formation of a universal and structuralist morality, with the thoughts of the philosopher Immanuel Kant and its influence for the theory of Piaget and Kholberg, in the moral development of a person divided in its specific stages, until the present studies that shows Bauman's conclusions about postmodern society and its social and personal implications. The consequences of social fragmentation in various aspects are brought to light in order to raise the reader's awareness and perception of their existence. An excess of contradictions is set forth for the reader to confront post modernity against a negative view of present actions, thus leading to reflection of what can be achieved, considering what we have today in our society.
\end{abstract}

Keywords: Kant; Piaget; Kohlberg, fragmentation; boredom culture 


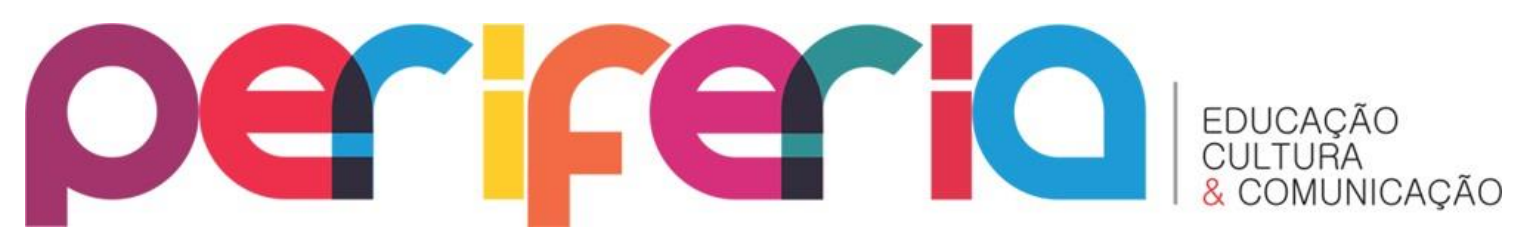

\section{INTRODUÇÃO}

A construção moral do indivíduo tem sido constantemente alvo de questionamentos, referentes às consequências de atos que trazem à tona diferentes pontos de vista sobre o que é moral ou imoral. Como é de se esperar, no meio educacional, esse assunto é de suma importância e vem cada vez com mais força no meio acadêmico, principalmente em um momento em que se torna questionável até que ponto se deve interferir com disciplina na educação dos jovens. Os debates acontecem como se todos tivessem razão, algo já registrado com muita antecedência.

Nos dois prefácios da Crítica da razão pura, Kant registra
magistralmente os motivos de seu descontentamento filosófico
em relação à metafísica racionalista de sua época. Deixa
claro, principalmente no primeiro prefácio, por que o debate
acerca dos problemas da metafísica se tornou um debate
estéril, em que todos têm aparentemente razão sem
chegarem a lugar nenhum. (DALBOSCO, 2011, p. 43)

Entre as contribuições podemos destacar as ideias de Immanuel Kant, criador da filosofia crítica. Ele acreditou que a educação fosse uma das melhores formas para a humanidade caminhar em direção a um mundo melhor, influenciou debates sobre atos serem morais ou não, e construiu através de seus livros a ideia da Universalização da Moral, onde coloca a contribuição de fatores externos para a tomada de decisões como de muita importância para analisar se podemos caracterizar um ato como sendo moral ou imoral, além de trazer a liberdade transcendental e a autonomia moral.

Nessas áreas podemos destacar trabalhos realizados por Lawrence Kohlberg, que ampliou os estudos sobre a moral e thes deu uma forma estruturalista e universalista, se utilizando de estágios morais. Influenciado por obras de Piaget e seu estruturalismo, Kohlberg deu assim continuidade aos estudos divulgados pelo livro "O Juízo Moral".

De acordo com Biaggio (2006), os estudos anteriores traziam a moral como algo que é imposto pelo mundo externo e posteriormente interiorizado 


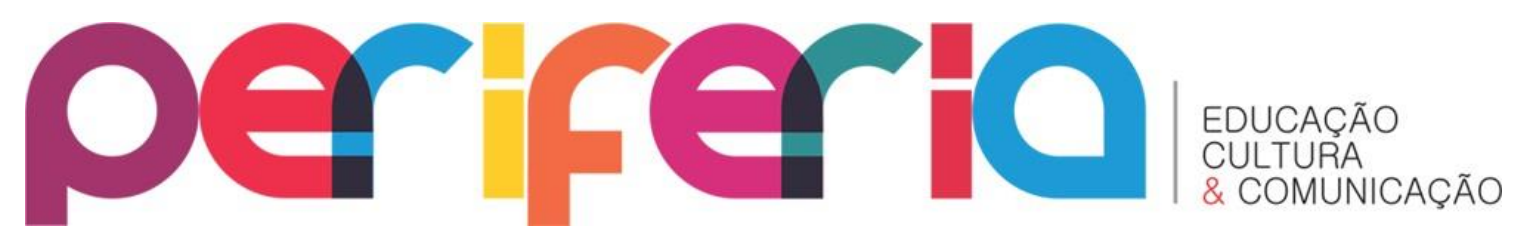

pelo indivíduo. Piaget trouxe um estudo que levava um indivíduo à tendência de autonomia moral através de estágios de desenvolvimento que se predominava "atitudes dominantes".

Os estágios foram identificados como:

Anomia: existe ausência da moral. Nesse estágio o indivíduo seria guiado pelas suas necessidades básicas. Quando existe a presença de regras em seu comportamento, elas não são obedecidas por consciência, mas sim pelos hábitos que de alguma forma atendem a suas necessidades.

Heteronomia: As regras existem, porém, quando seguidas, o são por imposição de alguma autoridade, e caso não sejam cumpridas, se estaria cometendo um erro.

Autonomia: Segue regras por vontade própria sem romper com a sua essência. A consciência, nesse estágio, existe, e não é mais necessário que ela seja imposta por uma autoridade exterior. 0 indivíduo conhece seu papel e seus acordos mútuos.

Nos seus estudos, Piaget colocou o desenvolvimento moral como um processo de construção que ocorreria no interior do indivíduo, e acabou se afastando da visão empirista que propõe a interiorização de regras da cultura do indivíduo.

A moralidade heterônoma predominaria em crianças de oito a nove anos e seria regida pela obediência e respeito unilateral ao adulto. A criança segue regras por ter medo da punição.

A moralidade autônoma predominaria em crianças de nove a onze anos e seria regida pelo respeito mútuo entre crianças, e com os adultos.

Ainda assim, os estudos de Piaget estavam focados em crianças, e concluíram que na adolescência elas tenderiam à autonomia, com ideias de justiça distributiva, em que todos recebem a mesma quantidade na distribuição independente das necessidades individuais, e de equidade, que seria o grupo de adequações a situações perante as condições do indivíduo.

Kohlberg, após trabalhar com adolescentes, sentindo-se limitado pelos conceitos de Heteronomia e Autonomia proposto pelos estudos de Piaget, 


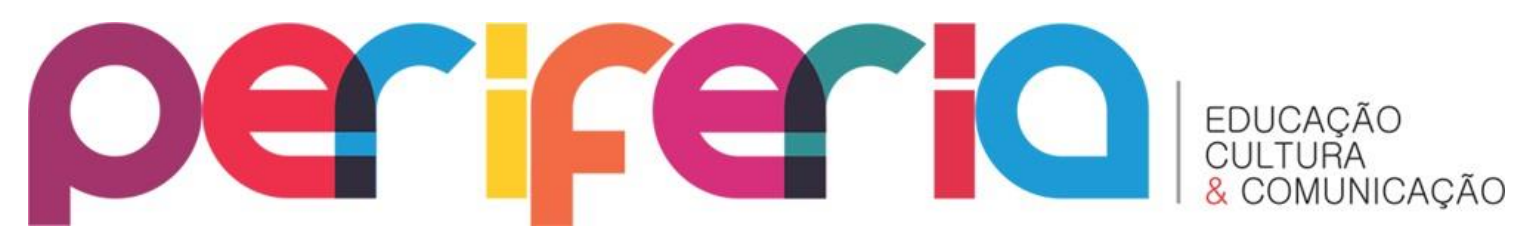

lançou mais seis estágios de raciocínio moral, que seriam divididos em três níveis: pré-convencional, convencional e pós-convencional. Destacou-se, pois não considerou como ponto terminal do desenvolvimento moral a internalização dos valores morais da sociedade. Apresentou, como exemplo de maturidade moral, o indivíduo que consegue entender que a justiça é diferente da lei, que é necessário modificar leis que são moralmente erradas. 0 poder de transcender os valores de sua cultura se destacaria, e ele então deixaria apenas de incorporá-los (ALVES, 2002).

Os estágios de desenvolvimento moral propostos estavam fora do campo das emoções. Foram utilizados como centro da moralidade a ideia de justiça e seus princípios, segundo as definições de Hare (1982 apud LEPRE; DE MORAIS; BATAGLIA, 2010). Seria necessário desenvolver características como solidariedade, confiança, responsabilidade coletiva e participação. O seu grupo passa a se transformar em comunidades cuja cultura é a valorização da vida, e que têm objetivos de educação individual.

Essa centralidade da justiça deriva também do trabalho de Piaget (1932/1994) sobre o desenvolvimento do julgamento moral, no qual ele definiu a moralidade como uma atitude de respeito pelas pessoas e pelas regras, aliando-se, portanto, a Kant (BIAGGIO, 2006, p. 37).

Diante de suas pesquisas foram compreendidos três níveis de desenvolvimento moral, para distinguir diferentes indivíduos e a maneira como eles se relacionam com as regras morais e com a expectativa da sociedade por uma regra universal. Dentro de seus níveis estão inseridos também seis estágios de desenvolvimento moral, dois dos quais estão compreendidos em cada nível, sendo consecutivamente mais complexos. "Cognitivamente mais complexo que o anterior, no sentido em que diferencia e integra perspectivas de um ponto de vista cada vez mais geral e abstrato." (LOURENÇO, 1992, p. 94.). 


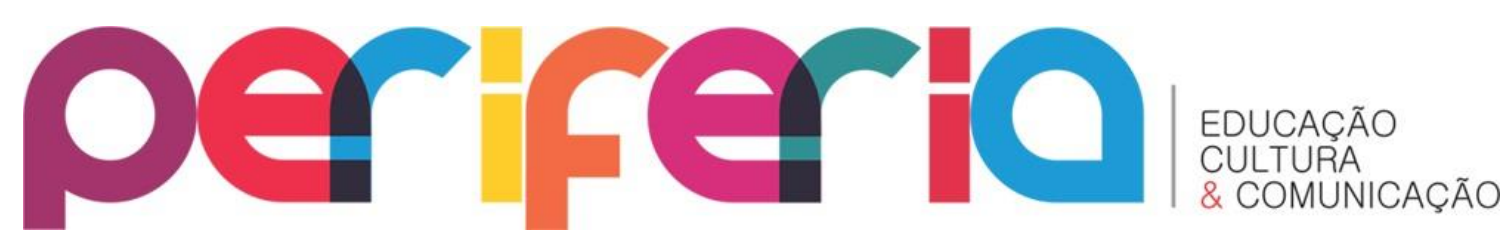

Os métodos utilizados por Kohlberg na avaliação de sua pesquisa foram os dilemas morais, para os quais o sujeito deveria apontar uma solução, argumentando e contra argumentando através de justificações racionais a entrevista clínica, e a utilização de vídeos para fazer a análise da mímica e dos gestos dos entrevistados.

O seu diagnóstico foi baseado em três pontos: 0 valor moral defendido, baseado pelo conteúdo da argumentação, como a apresentação da punição, lei, vida, liberdade, justiça, papéis afetivos e autoridades; a justificativa dos argumentos, estrutura e coerência da argumentação; a orientação sócio-moral do sujeito (ALVES, 2002).

De inúmeros estudos realizados, foram encontrados os mesmo três níveis diferenciados de desenvolvimento moral em sujeitos de diferentes culturas, como característica universal dos indivíduos, demonstrando como o sujeito se relaciona com a sociedade e suas expectativas.

\section{NÍVEIS E ESTÁGIOS DE DESENVOLVIMENTO MORAL}

A moralidade pré-convencional se caracteriza pela heteronímia, como uma moral que está externa a si, baseada em regras e leis que devem ser respeitadas para se evitar punições ou para satisfazer seus próprios desejos.

Sujeitos de todas as faixas etárias poderiam estar presentes nesse grupo, crianças, adolescentes e adultos, e uma grande parcela de delinquentes e criminosos. A norma moral não é interiorizada, ela é algo imposto para esses indivíduos e assim classificar se uma ação é justa ou não seria uma ponderação das consequências físicas e materiais.

\section{Estágio 1 - A moral do Castigo}

Para Sutherland (1996), esse estágio é caracterizado pelo pensamento pré-moral. Os estímulos seriam a origem do seu comportamento, e uma obediência a uma autoridade exterior absoluta. 


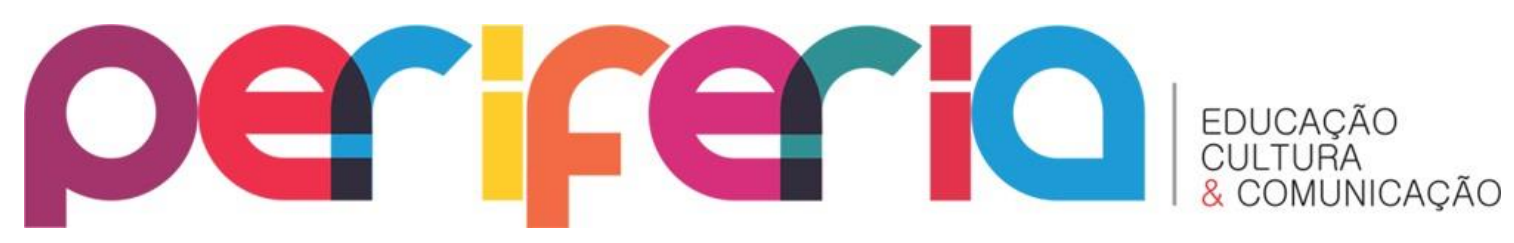

De acordo com Alves (2002), o indivíduo está preocupado em respeitar e obedecer a autoridade para não sofrer penalidades. "Numa reciprocidade latente, o castigo deve-se a uma má ação, e esta é tanto mais grave, tanto mais merecedora do castigo, quanto maior for o dano causado" (LOURENÇO, 1998 apud ALVES, 2002, p. 79).

Podemos concluir que o egocentrismo predominaria na sua perspectiva moral. A transgressão da moral levaria a receber castigos da autoridade externa, e seria para evitar castigos e penalidades, mais físicas que psicológicas, que o indivíduo tomaria suas decisões.

\section{Estágio 2 - A moral do interesse}

Esse estágio já compreende um maior desenvolvimento cognitivo do indivíduo, apesar de ainda fazer parte do primeiro nível, pois ele já compreende que existem situações de confronto, coordenando-se de modo individualista, concreto e com prudência (TISAK; TURIEL, 1984 apud LOURENÇO, 1992). Para Lourenço (1992) o indivíduo considera boas ações quando satisfazem seus interesses, desejos e necessidades, e porventura os do próximo, tendo assim um ponto de vista individualista e concreto.

A justiça e a moralidade estão centradas nas consequências, com uma perspectiva de lucro e não nas ações em si. 0 indivíduo tenta então alcançar o máximo de sua satisfação própria tentando reduzir o quanto possível suas penalidades. Uma relação de troca de preocupações pragmáticas em que, para Sutherland (1996), o indivíduo, apesar de possuir consciência do outro, coopera apenas com base em uma negociação. "A incidência generalizada é sobre os bens desejáveis. Se cooperar com os outros é um meio de obter, eu fá-lo-ei." (SUTHERLAND, 1996, p. 263).

A moralidade convencional se caracteriza por indivíduos que interiorizaram as normas e as expectativas sociais. Seus desejos individuais não relativizam mais o que pode ser justo ou injusto ao ponderar castigo ou punição. 0 sujeito leva em consideração o respeito do próximo ou do grupo 


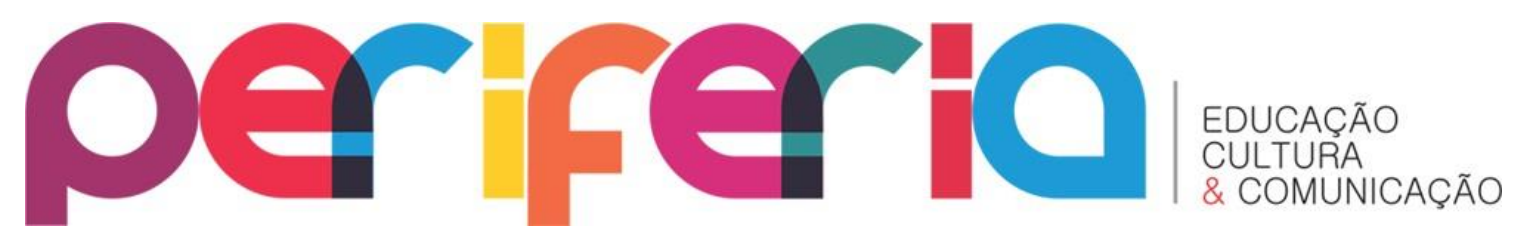

sobre si, e passa a ter uma orientação interpessoal na sua moralidade, levando as necessidades do grupo acima das suas individuais, para Alves (2002), procurando agir de modo a ser "bem visto" por outros. Segundo Kohlberg (1981), o indivíduo passa a procurar grupos que correspondem a suas expectativas sociais, em que todos procurem preservar a lealdade e a ordem.

\section{Estágio 3 - A moral do coração}

Nesse estágio a pessoa estaria a seguir normas e convenções sociais, por isso pode-se dizer que ela não se aprisiona apenas a seus próprios interesses. Sua moral passa a ser interpessoal e relacional, palavras chaves que darão um novo olhar a seu relacionamento com a sociedade, conhecendo o seu lugar.

"Incide-se mais sobre a solidariedade do grupo. A pessoa está agora consciente das outras no grupo de colegas e preocupa-se com a opinião delas no que diz respeito à sua pessoa." (SHUTERLAND, 1996, p.263).

A sua perspectiva moral estaria relacionada com a aceitação ou adaptação de um grupo, ou até mesmo de uma terceira pessoa, com a qual ela tem um relacionamento afetivo.

Para Lourenço (1992), imaginar-se no lugar do indivíduo seria a "regra de ouro", da qual o indivíduo se valeria para determinar suas ações, "a regra que manda tratar os outros como nós próprios gostaríamos de ser tratados se estivéssemos no lugar deles." (LOURENÇO, 1992, p. 101).

\section{Estágio 4 - A moral da lei}

Segundo estágio da moral convencional, se caracteriza por adotar um ponto de vista mais geral, segundo Lourenço, seguindo uma linha mais racional que relacional. Assim, se assume que existe um sistema social que deve ser mantido com seus direitos e deveres institucionais. 


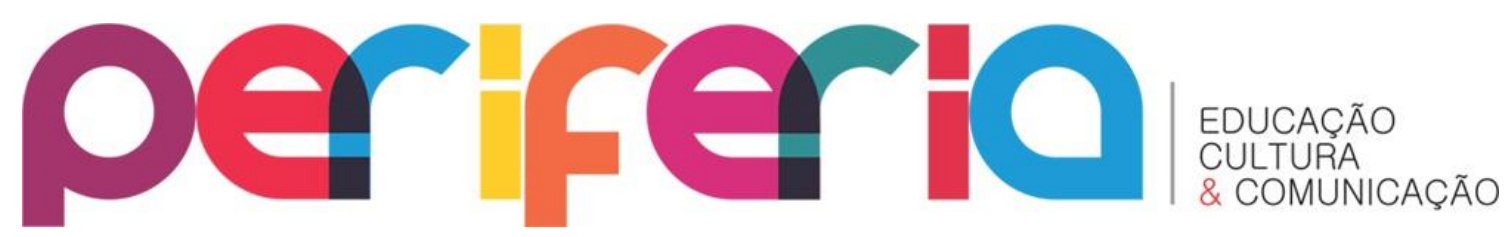

Diferentemente do estágio anterior, o indivíduo passa a se orientar pelas leis, para trazer ordem à estrutura da sociedade, e agora, consciente disso, precisa justificar seus atos por estar consciente de seu próprio comportamento moral perante a sociedade; assim se referiu Sutherland (1996, p. 263).

Diante da necessidade de se justificar, o indivíduo passa a se preocupar com as necessidades de um sistema imparcial, em que todos os cidadãos seriam iguais perante a lei para que existam "procedimentos que permitam a aplicação imparcial da lei e da justiça" (ALVES, 2002, p. 85). Ele admite que em uma relação de reciprocidade, direitos implicam em deveres (LOURENÇO, 1992).

A moralidade pós-convencional é regida pela autonomia e por princípios morais. Seria algo que apenas uma pequena parcela da população conseguiria alcançar, e na maioria, após os seus 20 ou 25 anos. Para Kohlberg (1981), o indivíduo sente por si próprio a necessidade de respeitar os direitos individuais fundamentais, sem ter como necessária a existência de uma imposição externa.

"Isto é, a manutenção da sociedade está para a moralidade convencional assim como a sua transformação está para a moralidade pósconvencional." (LOURENÇO, 1992, p. 93).

Ou seja, para este autor, o indivíduo compreende que existem as normas e que as relatividades também fazem parte, e há até casos em que as leis devem ser modificadas até desobedecidas, para a manutenção de princípios universais.

[...] para quem o valor moral das ações depende menos da sua conformidade às normas morais e sociais vigentes e mais da sua conformidade a princípios éticos universais, tais como direito à vida, à liberdade ou a justiça. (LOURENÇO, 1992, p.92). 


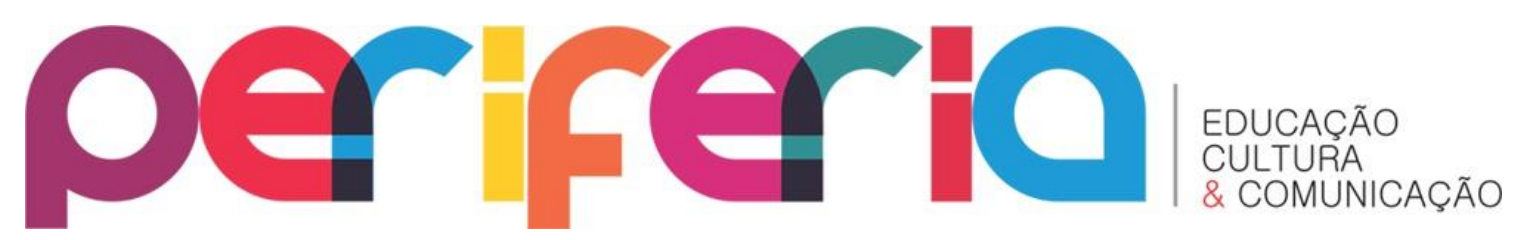

Estágio 5 - A moral do relativismo da lei

Segundo Kohlberg (1981), predomina nesse estágio a relatividade das normas. $O$ indivíduo percebe que existem situações em que as leis entrariam em conflito com princípios morais universais, estando assim mais disposto a respeitar os princípios, como direito à vida e à liberdade, orientando-se para o contrato social e para o bem comum, através de igualdade, equidade e reciprocidade, sem se afastar das leis universais a que se referem a valores morais não-relativos.

Lourenço (1992) afirma que para esses indivíduos a justiça só é alcançada quando ela é operada em concordância com os direitos fundamentais do Homem, e a igualdade apenas existirá quando as pessoas tiverem direitos iguais. "[...] A perspectiva destes sujeitos é mais de transformação da sociedade que da sua manutenção" (LOURENÇO, 1992, p.108).

\section{Estágio 6 - A moral da razão universal}

Esse seria o último estágio de desenvolvimento para Kohlberg, em sua teoria original, que seria abandonada como uma realidade empírica, e seria colocada como um ideal de desenvolvimento moral. Os indivíduos que se encontrassem nesse estágio passariam a ocupar o estágio 5 , de maneira global.

Lourenço (1992. p. 107) afirma que nesse estágio o indivíduo teria uma "(...) consciência clara da universalidade, normatividade e reversibilidade dos princípios éticos", o que seria a diferença em relação ao estágio anterior, quando o sujeito poderia tomar suas decisões em direção à utilidade social e à justiça, e, portanto, ainda não teria completa autonomia moral.

Nesse processo, "os fins não justificam os meios", ou seja, o bem maior não seria a sobreposição dos princípios de justiça, o que levaria a pensar que não é aceitável sacrificar uma vida para se salvar muitas outras. 


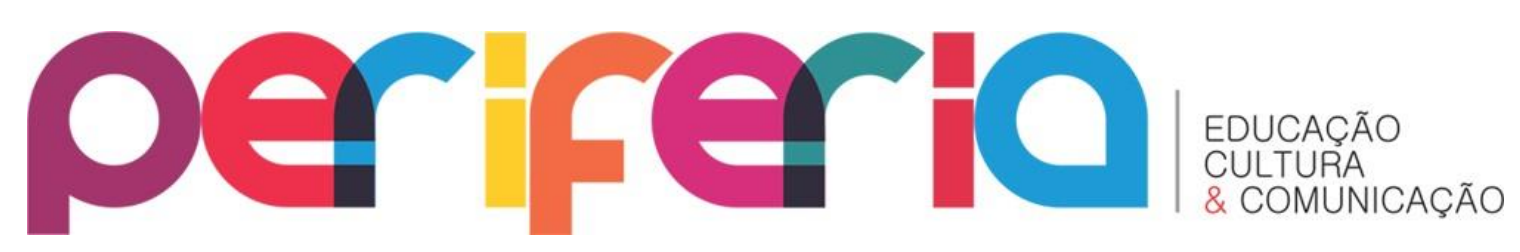

“(...) é a de um ponto de vista moral que todos os seres humanos devem tomar uns para os outros como pessoa autônomas, livres e iguais, havendo procedimentos que asseguram a honestidade, imparcialidade e reversibilidade na tomada de perspectiva". (COLBY; KOHLBERG, 1987, apud ALVES, 2002, p.88).

\section{A IMPORTÂNCIA DA VERGONHA}

Nos limitaremos a alguns aspectos que estão relacionados ao desenvolvimento moral e têm relevância significativa para o tema da moralidade. Curiosamente, apesar de ser um sentimento penoso e motivo muitas vezes de suicídios, a vergonha tão tem sido motivo de muita atenção para pesquisadores.

Veremos agora dois tipos de sentimentos que causam dor psíquica, relacionados à ela.

\section{Vergonha de exposição}

Esse sentimento é experimentado quando o indivíduo se insere em um momento no qual é necessário se expor, sem necessariamente ter de outros um juízo negativo.

Como exemplo, quando uma pessoa é aclamada por um público ao fazer algo valoroso, como uma exposição de trabalho, ela pode sentir vergonha por estar frente a um público, mesmo tendo uma resposta positiva.

\section{Vergonha judicativa}

Sentimento que tem como fonte um juízo negativo, que causa maior dor psíquica e difere do anterior. Será de maior importância e contribuição para falarmos de moral. 


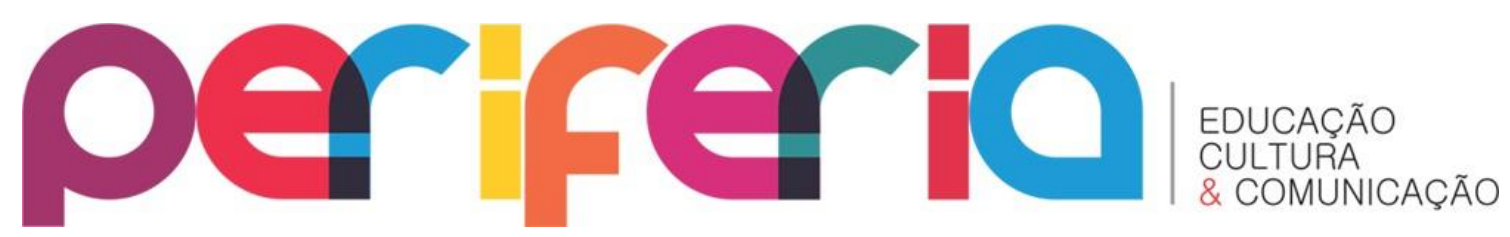

Para que isso aconteça é necessário que o juízo negativo ocorra, sendo da própria pessoa ou de outro, e podendo desencadear um maior aprofundamento do sentimento de quem sofre.

Hoje é muito comum entre jovens usarem jogos para passar seu tempo, muitas vezes de forma competitiva. Um jogador, ao término do jogo, pode sofrer críticas pelos seus companheiros de time. Ele pode desprezá-las por não fazer juízo, por considerar os outros jogadores sem qualificação o suficiente, ou seja, piores que ele. Mas caso sinta vergonha de suas ações é porque faz juízo crítico de si, e as palavras acabam tendo relevância quando são direcionadas para as suas ações. Nessa mesma linha de raciocínio, um jogador pode sentir vergonha sozinho, ao ver o seu replay, pode considerar suas ações durante o jogo medíocres, mesmo recebendo de outras pessoas elogios, julgando negativamente, mesmo que outras pessoas não saibam, suas ações durante o jogo.

Logo, podemos concluir que o juízo negativo incide sobre o "eu". Como exemplo podemos citar o jogador que chega à conclusão de que suas ações durante o jogo foram medíocres, e assim pode pensar que não é um jogador com a qualidade que esperara ser. Nesse caso, a imagem construída de si é o motivo de sentir vergonha. Também é possível sentir vergonha sem necessariamente praticar uma ação. A pessoa está sub judice de seu amor próprio, o elemento que desencadearia uma dor psíquica por fazê-la achar que é privada de beleza física.

Supondo que o jogador sofreu uma derrota ao término do jogo, caso ele tenha lutado para que isso não ocorresse, veremos então um jogador que não atingiu a meta que acreditara ser possível, e mais ainda, suas ações não corresponderam ao que idealizara. Existe nesse processo um perceptível distanciamento do que é idealizado e o que ocorre durante a prática, uma distância de ideais valorativos. Os ideais valorativos são a referência ou a medida que o juízo negativo incide sobre o "eu".

Segundo Elizabeth Harkot-de-La-Taille (1999 apud DE LA TAILLE, 2002), existem dois tipos de vergonha, a vergonha retrospectiva e a vergonha 


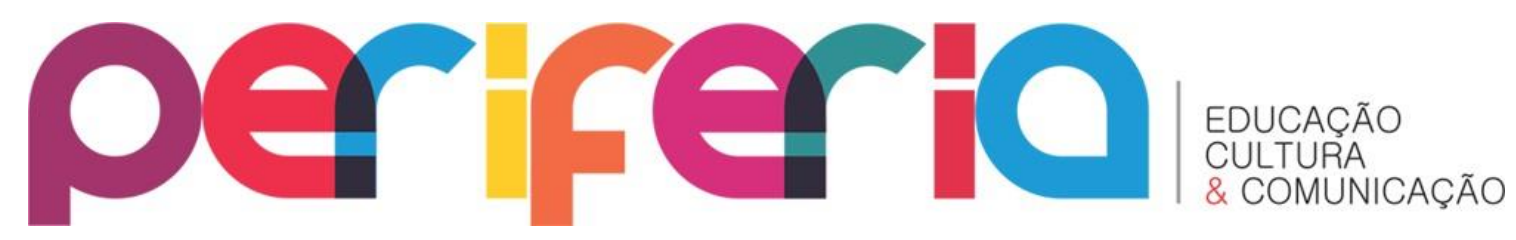

prospectiva. Enquanto a retrospectiva está relacionada a um fato passado, a prospectiva se relaciona com um fato futuro que, caso ocorresse, seria motivo para se sentir vergonha, funcionando assim como um inibidor e regulador de condutas.

E para concluir, a vergonha pode incidir sobre valores morais ou não, como a vergonha de se perder um jogo e a vergonha de cometer atos injustos.

\section{VIDA FRAGMENTADA E DESENVOLVIMENTO MORAL}

Bauman (2003 apud DE LA TAILLE, 2009) desenvolveu um livro chamado "Vida em migalhas", no qual usou a analogia de um turista e um peregrino para explicar como a nossa vida se parece mais com a de um turista, por apresentar como característica fragmentos de espaço, de saber, de tempo e de sociabilidade.

\section{Fragmentação do espaço}

Hoje vivemos em um mundo em que as informações chegam com bastante velocidade, e consequentemente, uma pessoa, durante um noticiário, ouve diferentes locais sendo destaque durante um conjunto de notícias, por exemplo ao ligar uma televisão. A minoria dessas pessoas, contudo, consegue identificar em um mapa onde ficam tais lugares, como o Haiti, o Afeganistão e a Síria.

\section{Fragmentação do tempo}

Ao ouvir sucessivas notícias as pessoas deixam a que acabou de acontecer para trás e vivem a nova, e assim por diante, sem que isso tenha um fim. Isso levou Paulo Vanzolini com a escrever, em sua canção "Cara Limpa": "vivendo o dia-a-dia ao invés da vida inteira". Podemos também escrever um conhecido verso dos Titãs e também título da música "A melhor 


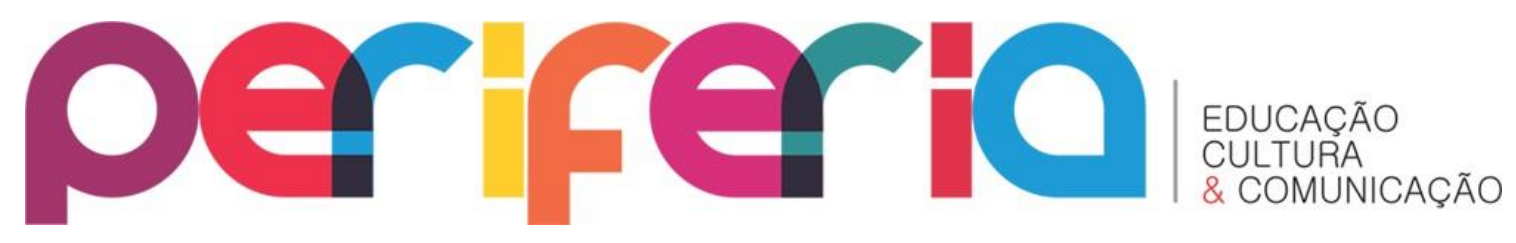

banda de todos os tempos da última semana". O historiador Hobsbawn (1995 apud DE LA TAILLE, 2009) escreveu que a maioria dos jovens vivem o "eterno presente", e assistimos todos os dias à destruição do passado, sendo que quase todos os jovens crescem sem relação alguma com ele.

\section{Fragmentação do saber}

De duas formas a fragmentação do espaço e do tempo incidem sobre a fragmentação do saber.

A primeira é a relevância da informação sobre o conhecimento. Quando se abre uma página de rede social, atualmente, se pode ter infinitas notícias desconectadas entre si, e com a nova tendência do jornal eletrônico, se escreve em poucas palavras e com bastante superficialidade e agilidade, para que a notícia, ou melhor, a informação, seja o mais "fresca" possível. As notícias não perduram, sua relevância logo tem um fim quando são substituídas por novas.

A segunda é a desvalorização da informação. Esquecer acaba sendo a condição da atual adaptação, e o aprender acaba perdendo sua relevância diante disso, segundo Bauman (2004).

Podemos citar também, como exemplo, uma infinidade de pessoas que estudam para o vestibular ou para concursos públicos, vendo durante um breve período de suas vidas um conteúdo extenso, sendo que após atingir seus objetivos, esquecerão esse conhecimento, que será substituído por novos conhecimentos, de uso na sua profissão.

\section{Fragmentação da relação social}

As relações sociais têm caído na superficialidade dos novos tempos. Para Aubert (2006 apud DE LA TAILLE, 2009) as relações, por serem construídas em uma sociedade em que tudo muda muito rápido, têm na sua fragilidade uma constante. A todo tempo cresce o número de pessoas 


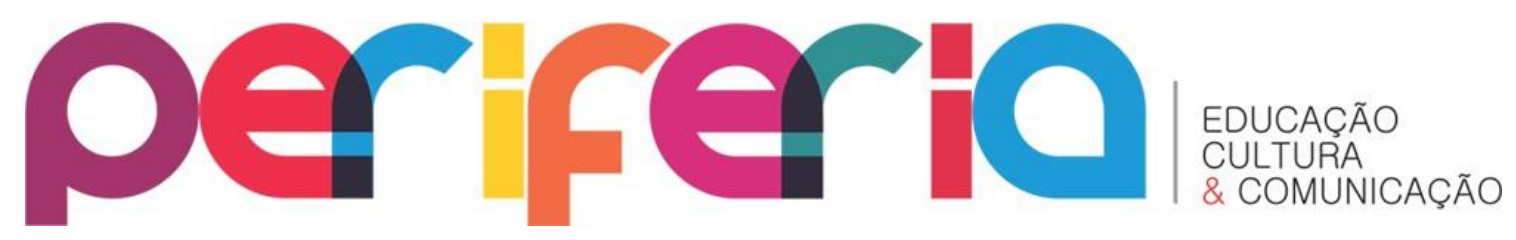

entrando em nossas vidas, e existem inúmeras formas de acesso que se pode utilizar para chegar a esses fins, como as redes sociais, que são o meio de maior destaque atualmente.

Vivemos um momento da história em que se pode ter acesso com muita facilidade às pessoas, mas ao mesmo tempo, em que elas estão mais distantes umas das outras. A carência de profundidade leva as relações sociais a padecerem na sua fragilidade, o que levou Bauman (2004) a criar a expressão "amor líquido".

\section{CONSEQUÊNCIAS DA FRAGMENTAÇÃO PARA A MORAL}

A primeira consequência que podemos destacar será em relação aos aspectos sociais. A moral que incide sobre as relações humanas está diretamente ligada à sua profundidade de conhecimento e interação com o próximo, logo, o respeito, a dignidade, e o reconhecimento de seus direitos serão afetados pela superficialidade de suas relações.

Dejours e Bèngue (2010) fizeram estudos em relação à medicina do trabalho, e constataram que o número de suicídios em empresas subiu e estava relacionado com o tipo de relação dentro do local de trabalho. Quando uma pessoa passa por alguma dificuldade no seu trabalho e chega ao desespero, seus colegas não se solidarizam com a situação para tentar ajudar, e muitas vezes nem notam.

A segunda consequência será a notória relativização e achatamento de valores. A moral, sendo um valor universal, deve ser conservada, segundo Piaget (1994). Quando um valor moral é relativizado para justificar atos imorais, a moral universal deixa de existir e passa a depender de um contexto, que pode ser justo ou não, certo ou errado, bom ou ruim. Um lugar onde tudo é possível pode ser um lugar onde não existem valores morais universais, um lugar onde as pessoas teriam mais dificuldades para achar um sentido para suas vidas, de modo a se distanciarem cada vez mais do suicídio. 


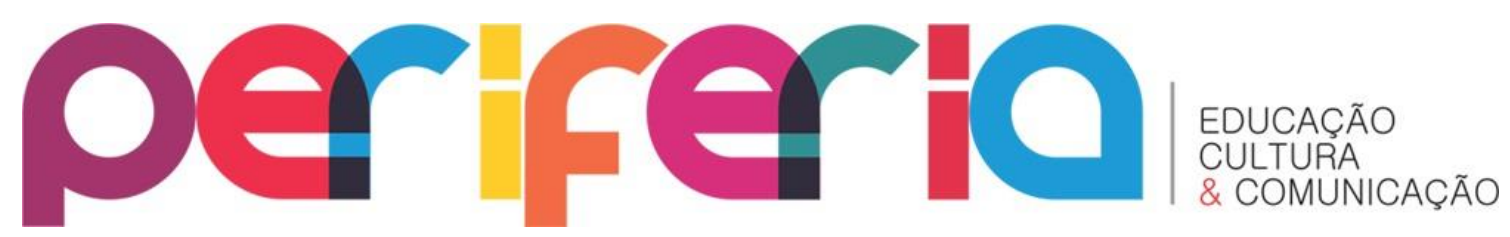

A terceira consequência é o que Bauman (1998) chamou de "identidade palimpsesto", o que incide sobre a ética, a identidade que o sujeito se atribui, mas para quem não tem valores morais, e muito menos poderia conservá-los diante da relativização e achatamento de valores, não restará nada mais do que fragmentos de sua identidade, e portanto, não será tão fácil tomar um rumo em sua vida.

Como quarta e última consequência, está a chamada "cultura do tédio", acompanhada da "cultura da vaidade". O vaidoso carece de valores morais. Por não ter profundidade em seu mundo, seus valores estão associados ao que aparenta ser para outras pessoas, assim ficando em um dos níveis mais baixos de desenvolvimento moral. Sua identidade está associada às celebridades que cultua, e não a pessoas que tiveram trajetórias inspiradoras, pois de alguma forma é necessário estudo e reflexão para ter esse tipo de proximidade. Consumista de moda, por ser ávido pela aparência, deseja as marcas que são símbolo de sucesso e dão a eles o destaque desejado.

\section{CONSIDERAÇÕES FINAIS}

Vivemos em uma sociedade que tem dado passos largos para o retrocesso moral, ainda que o devido acesso a obras, museus, livros e pessoas diferenciadas seja facilitado de inúmeras formas. A profundidade de relações com o mundo deveria tender a ser cada vez mais complexa, e a favorecer o desenvolvimento pleno do indivíduo. Porém, o que se encontra é um quadro negativo, com fortes tendências contraditórias, e é sobre esse paradoxo que devemos atuar para chegarmos a uma moral, autônoma, justa, consistente, digna e que dê sentido às vidas, para que de alguma forma seus valores representem uma vida que vale a pena ser vivida.

No entanto, em uma sociedade fragilizada pela fragmentação e pelo enfraquecimento da moral, se pressupõe um futuro caótico, onde as pessoas não acreditam nas instituições e em seus valores, mas sim em seu próprio umbigo, ou ainda onde as pessoas não reconhecem elos entre seus valores e os 


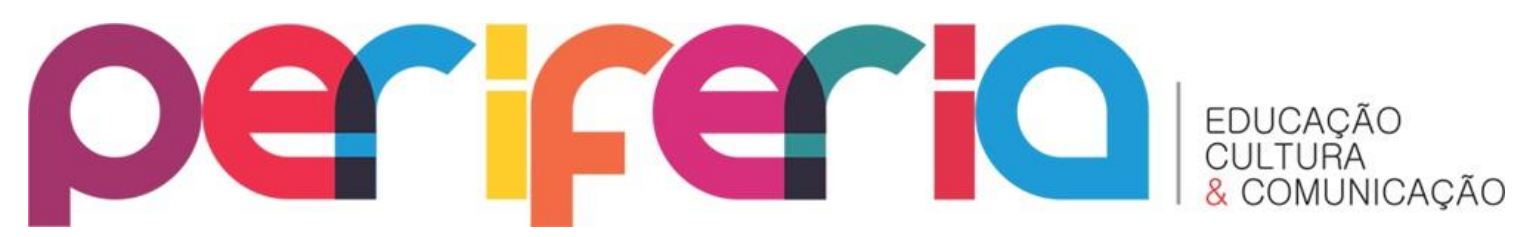

fatos do mundo. Seremos lançados ao abandono individual ou à farsa coletiva. Em ambas as situações, o certo, o bom, o justo, deixam de ser valores universais e passam a ser relativizados individualmente, afetando negativa e definitivamente as relações sociais.

Dessa forma, o presente artigo não pretende ser um apontamento de verdades. Muito pelo contrário, procura destacar os autores que dão visibilidade à temática, reforçando a necessidade de tornar o tema do desenvolvimento moral um debate acadêmico de alta relevância, em face da saúde mental da coletividade.

\section{REFERÊNCIAS BIBLIOGRÁFICAS}

ALVES, P. O desenvolvimento Moral do Adolescente: contributos em psicopedagogia. 2002. Dissertação de Mestrado não publicada - FPCE, Universidade de Coimbra, Coimbra, 2002.

BAUMAN, Z. O mal-estar da pós-modernidade. Rio de Janeiro: Zahar, 1998.

BAUMAN, Z. Amor líquido: sobre a Fragilidade dos laços humanos. Rio de Janeiro: Zahar, 2004.

BIAGGIO, A. M.B. Lawrence Kohlberg. São Paulo: Moderna, 2006.

DALBOSCO, C. A. Kant \& a educação. Rio de Janeiro: Autêntica, 2011.

DEJOURS, C.; BÈNGUE, F. Suicídio e trabalho - o que fazer? Brasília: Paralelo 15, 2010.

DE LA TAILLE, Y. Formação ética: do tédio ao respeito de si. São Paulo: Artmed, 2009.

DE LA TAILLE, Y. O Sentimento de Vergonha e suas Relações com a Moralidade. Psicologia: Reflexão e Crítica, v. 15, n. 1, p. 13-35, 2002.

KOHLBERG, L. The Philosophy of Moral Development. Nova lorque: Harper \& Row, 1981.

LEPRE, R. M.; DE MORAIS, A.; BATAGLIA, P. U. R. A teoria de Kohlberg sobre o desenvolvimento do raciocínio moral e os instrumentos de avaliação de juízo e 


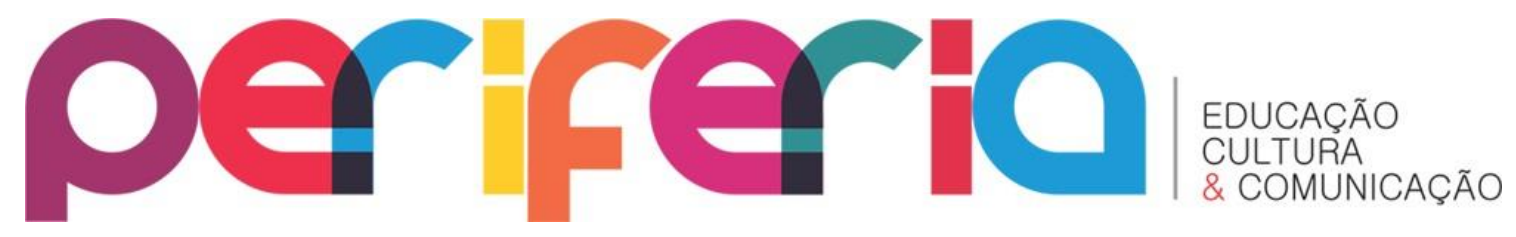

competência moral em uso no Brasil. Estudos de psicologia, v. 15, n.1, p. 2532, 2010.

LOURENÇO, O. M. Psicologia do desenvolvimento moral: teoria, dados e implicações. Coimbra: Almedina, 1992

PIAGET, J. O juízo moral na criança. São Paulo: Summus, 1994.

SUTHERLAND, P. O desenvolvimento cognitivo actual. Lisboa: Instituto Piaget, 1996. 